\title{
A cell engineering approach to enzyme-based fed-batch fermentation
}

\author{
Michael Sibley and John M. Ward ${ }^{*}$ (D)
}

\begin{abstract}
Background: A fundamental problem associated with E. coli fermentations is the difficulty in achieving high cell densities in batch cultures, attributed in large part to the production and accumulation of acetate through a phenomenon known as overflow metabolism when supplying enough glucose for the cell density desired. Although a fedbatch configuration is the standard method for reducing such issues, traditional fed-batch systems require components which become problematic when applying them at smaller scale. One alternative has been the development of a system whereby the enzymatic degradation of starch is used to release glucose at a controlled rate. However, to date, amylolytic enzymes have only been applied to the culture exogenously, whereas our goal is to design and construct a self-secreting amylolytic chassis capable of self-regulated enzyme-based fed-batch fermentation.
\end{abstract}

Results: A putative glucoamylase from C. violaceum has been cloned and expressed in E. coli BL21(DE3) and W3110, which exhibits significant glucose releasing amylolytic activity. Extracellular amylolytic activity was enhanced following a replacement of the enzymes native signal peptide with the DsbA signal sequence, contributing to a glucoamylase secreting strain capable of utilising starch as a sole carbon source in defined media. Introduction of PcstA, a glucose sensitive $\mathrm{K} 12$ compatible promoter, and the incorporation of this alongside $C$. violaceum glucoamylase in $E$. coli W3110, gave rise to increased cell densities in cultures grown on starch $\left(\mathrm{OD}_{600} \sim 30\right)$ compared to those grown on an equivalent amount of glucose $\left(\mathrm{OD}_{600} \sim 15\right)$. Lastly, a novel self-secreting enzyme-based fed-batch fermentation system was demonstrated via the simultaneous expression of the C. violaceum glucoamylase and a recombinant protein of interest (eGFP), resulting in a fourfold increase in yield when grown in media containing starch compared with the glucose equivalent.

Conclusions: This study has developed, through the secretion of a previously uncharacterised bacterial glucoamylase, a novel amylolytic E. coli strain capable of direct starch to glucose conversion. The ability of this strain to achieve increased cell densities as well as an associated increase in recombinant protein yield when grown on starch compared with an equivalent amount of glucose, demonstrates for the first time a cell engineering approach to enzymebased fed-batch fermentation.

Keywords: Enzyme-based fed-batch fermentation, Bacterial glucoamylase, Starch to glucose conversion, Cell engineering for bioprocess

*Correspondence: j.ward@ucl.ac.uk Department of Biochemical Engineering, UCL, Gower Street, London WC1E 6BT, UK

\begin{abstract}
Background
Overflow metabolism is a major contributory factor limiting cell densities and recombinant protein yields in E. coli fermentations. During rapid glucose uptake in aerobic conditions, the flux of acetyl-coA through $E$. coli central metabolism is diverted away from the tricarboxylic acid (TCA) cycle and towards the production of
\end{abstract} author(s) and the source, provide a link to the Creative Commons licence, and indicate if changes were made. The images or other third party material in this article are included in the article's Creative Commons licence, unless indicated otherwise in a credit line to the material. If material is not included in the article's Creative Commons licence and your intended use is not permitted by statutory regulation or exceeds the permitted use, you will need to obtain permission directly from the copyright holder. To view a copy of this licence, visit http://creativecommons.org/licenses/by/4.0/. The Creative Commons Public Domain Dedication waiver (http://creativecommons.org/ publicdomain/zero/1.0/) applies to the data made available in this article, unless otherwise stated in a credit line to the data. 
acetate [1]. The resulting accumulation of acetate lowers media $\mathrm{pH}$, leading to both a reduction in growth [2] and a reduction in recombinant protein yield [3]. To achieve the cell densities required for many purposes batch growth, where all the glucose is added to the media at the start, will lead to overflow metabolism and acetate build up. By limiting the availability of glucose, the specific growth rate of cells within the culture can be reduced below the threshold required to initiate overflow metabolism, therefore minimising the production and accumulation of acetate. This concept of substrate limited fed-batch fermentation is a commonly used method to minimise the detrimental effects of overflow metabolism and increase cell densities and recombinant protein yields. Traditional systems vary extensively in the manner of substrate delivery; some are programmed with pre-determined feed rates e.g. constant or exponential, while others rely on automatic feedback control [4]. Regardless of the mechanism, traditional fed-batch fermentation is often an impractical solution for smaller scale fermentations such as those in shake flasks, owing to the sophistication of the control systems required, as well as other technical difficulties including unsatisfactory flow and mixing of the small, concentrated feed volumes. Many of these issues are being challenged through the development and increased availability of miniature bioreactors, for example the ambr ${ }^{\circledR} 250$ from Sartorius or the DASbox ${ }^{\circledR}$ from Eppendorf, however shake flasks still provide an inexpensive and effective way of reproducibly performing many types of industrially-relevant cell cultivations for process development, and are therefore still widely used across industry and academia [5].

An alternative approach to the traditional fed-batch fermentation concept, and one which can be applied directly to shake flasks, has been the development of substrate delivery via an internal supply mechanism [6, 7]. An example specific to glucose supply uses silicone elastomer discs containing glucose crystals which, when immersed in media, release glucose by diffusion [8]. Another method has been the development of enzymebased fed-batch fermentation, in which glucose is provided to the culture via the enzymatic degradation of starch i.e. metabolically inactive polysaccharide is converted into metabolically active monosaccharide following the addition of an amylolytic enzyme $[9,10]$. This technology, referred to as EnBase ${ }^{\circledR}$, has been commercially developed by BioSilta [11] as EnPresso ${ }^{\circledR}$ media, and uses an amyloglucosidase or glucoamylase (E.C.3.2.1.3) isolated from Aspergillus niger to convert starch to glucose, with the rate of glucose release determined by the concentration of glucoamylase supplied to the culture. Original experimental work used a two phase media system consisting of mineral salt medium (MSM) combined with starch infused agar layers [10], providing sufficient concentrations of starch to achieve high cell densities while also avoiding issues associated with solubility. The starch infused agar layers allowed starch to continuously dissolve into the media over time. Developers were able to infuse gels with $100 \mathrm{~g} / \mathrm{L}$ starch, which, based on the assumption that one gram of glucose could yield approximately $0.5 \mathrm{~g}$ dry cell weight, they calculated would be enough to give a theoretical cell density of $30 \mathrm{~g} / \mathrm{L}$ dry cell weight, equivalent to an $\mathrm{OD}_{600}$ of approximately 100 . Optimised glucoamylase concentrations gave rise to cell densities with $\mathrm{OD}_{600}$ values of 20 to 30 , or approximately 6 to $9 \mathrm{~g} / \mathrm{L}$ dry cell weight, a significant advantage over more traditionally used complex media such as LB [10].

Despite these advantages, systems to date have been limited as they require the addition of an externally supplied amylolytic enzyme. In this study we describe the development and application of a novel self-secreting amylolytic $E$. coli strain, providing the first demonstrated example of a cell engineering approach to enzyme-based fed-batch fermentation. The scope of the work described here includes the identification and characterisation of a previously unreported bacterial glucoamylase cloned from Chromobacterium violaceum, the regulated expression and secretion of this glucoamylase from E. coli, and finally the application of this amylolytic strain to enhance shake flask bioprocesses resulting in increased cell densities and recombinant protein yield.

\section{Results}

\section{Identification and characterisation of novel bacterial glucoamylases}

Glucoamylases are able to successively hydrolyse the terminal $\alpha-1,4$ glycosidic links from the non-reducing ends of polysaccharides [12], predominantly generating glucose as opposed to other maltodextrins. They are the enzyme of choice for current enzyme-based fed-batch fermentation systems, however, the majority of previously characterised glucoamylases, and those which are primarily used for industrial purposes, are of fungal origin, largely from Aspergillus niger and Rhizopus oryzae [13]. For the most part, fungal glucoamylases are highly glycosylated, which is thought to be important for their stability [14], meaning they are often difficult to successfully express in E. coli. A notable exception being the heavily glycosylated glucoamylase STA1 from Saccharomyces cerevisiae (var. diastaticus), which has been successfully expressed in E. coli previously as a nonglycosylated version [15]. However, owing to the lack of examples in the literature, it seemed appropriate to identify putative bacterial glucoamylases, to facilitate expression and secretion within an $E$. coli host. One of the few examples of a bacterially derived glucoamylase which 
has previously been expressed in E. coli is the thermostable glucoamylase (TtcGA) from Thermoanaerobacter tengcongensis MB4 [16]. Using the carbohydrate-active enzymes (CAZy) database [17], putative bacterial glucoamylases from Glycoside Hydrolase Family 15 were identified and selected based on their relatedness to the T. tengcongensis glucoamylase [Molecular Evolutionary Genetics Analysis version 7.0 (MEGA7) software] the relationship of these bacterial glucoamylases is shown using the tree in Fig. 1. Two novel glucoamylases from $D$. geothermalis and C. violaecum were then cloned along with the $T$. tengcongensis derived glucoamylase, into pET29a and pET28a expression vectors. We found no differences in expression when either pET28 or pET29 was used. The relationship between the three glucoamylases studied in detail here (the ones in red in Fig. 2) are shown in the alignment in Additional file 1: Fig. S1.

Both starch degradation and glucose accumulation assays were used to determine cell free extract activities for D. geothermalis, T. tengcongensis, and C. violaecium glucoamylases. Each enzyme produced glucose as the predominant hydrolysis product, with the combined

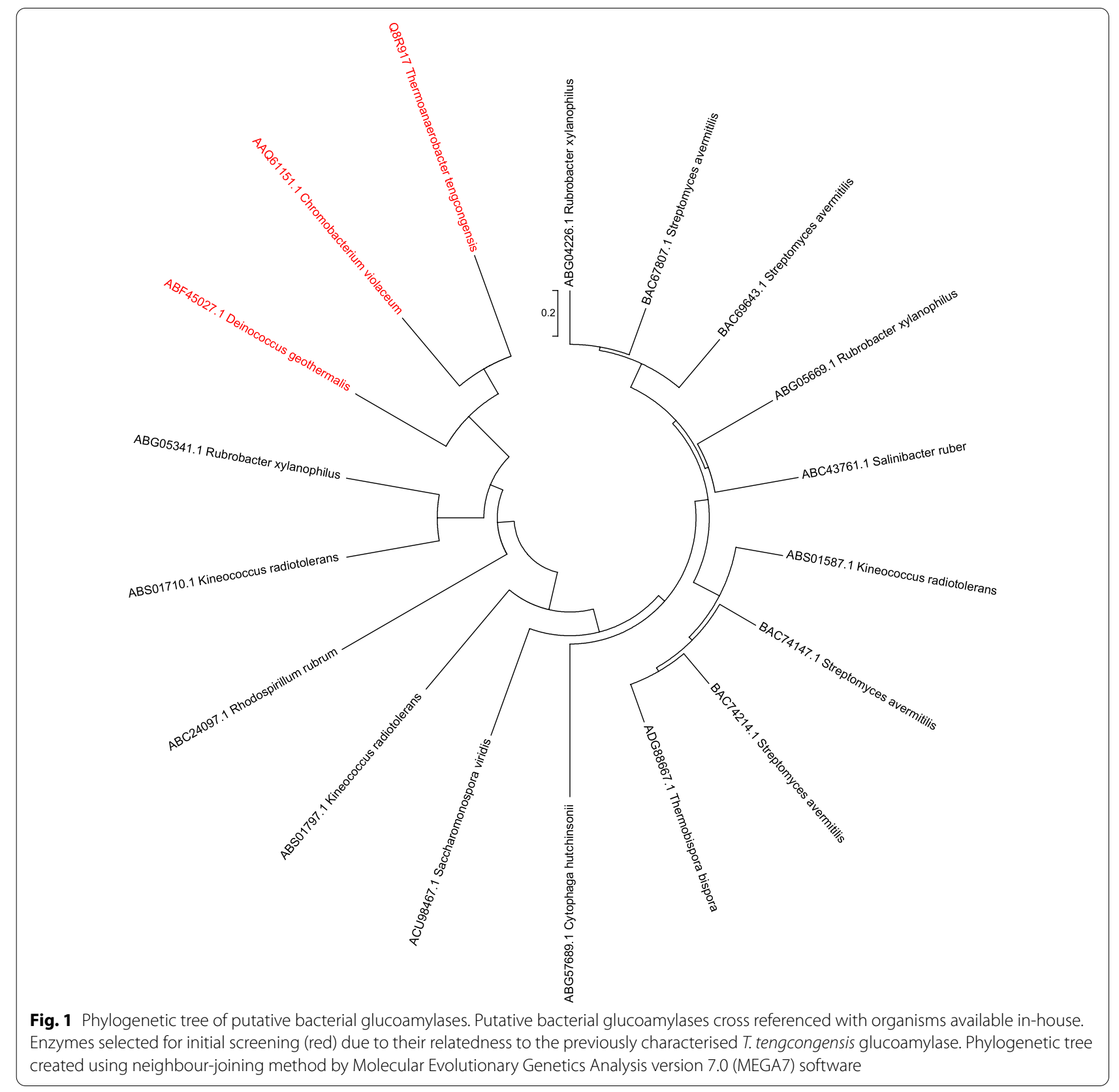


a

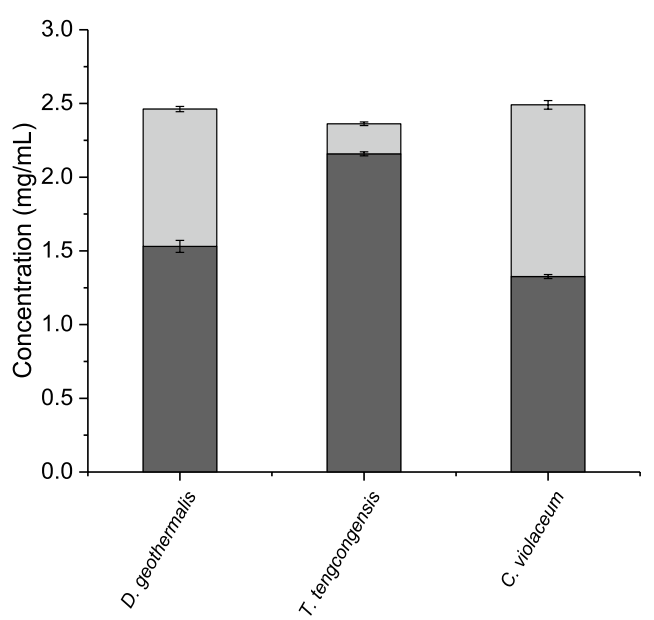

b

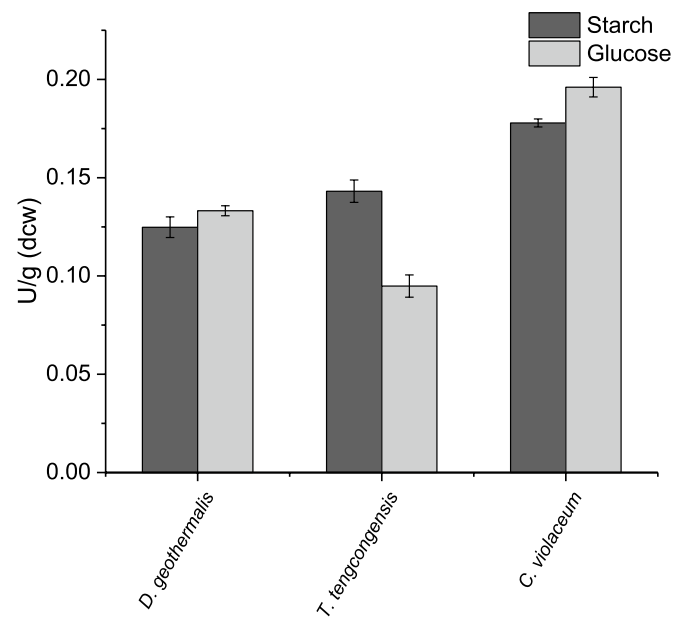

Fig. 2 Starch degradation and glucose accumulation from cell free extracts of D. geothermalis, T. tengcongensis and C. violaceum glucoamylases. Cell free extracts from BL21(DE3) harbouring either pQR1706 (D. geothermalis glucoamylase, pQR1707 (T. tengcongensis glucoamylase), or pQR1708 (C. violaceum glucoamylase), induced with $0.4 \mathrm{mM} \mathrm{IPTG}$ at an $\mathrm{OD}_{600}$ of 0.8 and grown in TB for $24 \mathrm{~h}$ at $25^{\circ} \mathrm{C}, 180 \mathrm{rpm}$. a Concentration (mg/mL) of remaining starch (dark grey) and accumulated glucose (light grey) following $1 \mathrm{~h}$ of amylase assay for each CFE. b Starch degrading activity in units (dark grey) defined as the disappearance of $1 \mathrm{mg} / \mathrm{mL}$ of starch/iodine complex per minute per gram of dry cell weight, and glucose accumulating activity in units (light grey) defined as accumulation of $1 \mathrm{mg} / \mathrm{mL}$ of glucose per minute per gram of dry cell weight, for each CFE. Starch degradation in amylase assay determined by the change in absorbance of starch/iodine complex at $600 \mathrm{~nm}$, glucose accumulation measured using HPAEC-PAD analysis. Error bars represent standard deviation, $n=3$

mass of remaining starch and accumulated glucose at an assay time of $1 \mathrm{~h}$ approximately equalling the initial concentration of starch $(2.5 \mathrm{mg} / \mathrm{mL})$ within the assay (Fig. 2a). A disparity between the rates of starch degradation and glucose accumulation was evident for the $T$. tengcongesis glucoamylase, but not for the $D$. geothermalis or the C. violaecium glucoamylases (Fig. 2b). The increased rate of starch degradation compared with glucose accumulation seen with the T. tengcongensis glucoamylase indicated that the latter two enzymes had lower endo-acting activity, and a cleaner hydrolysis product profile (Fig. 3).

With both the D. geothermalis and C. violaecium glucoamylases giving rise to suitable hydrolysis product profiles, each of the enzymes were investigated for their secretory potential based on targeting them to the periplasm and relying on outer membrane permeability for release into the extracellular media. If present, native signal sequences were examined, as was the addition of exogenous signal peptides DsbA (originally derived from thiol disulfide oxidoreductase found in many bacterial species including E. coli) $[18,19]$ or PelB (originally derived from the pectate lyase B from Pectobacterium carotovorum) [20], directing proteins through the SRP [21] or Sec [22] pathways respectively. The D. geothermalis glucoamylase did not contain a native secretory signal sequence (SignalP 4.1) and as a result did not display any extracellular activity (Fig. 4a). Neither the addition of exogenous signal sequences DsbA ( $\mathrm{pQR} 1709$ ) or PelB (pQR1710), increased extracellular activity. In fact, their additions diminished cell free extract activities. In contrast, the C. violaecium glucoamylase did contain a native secretory signal sequence and displayed extracellular activity without modification (Fig. 4b). This activity was eliminated following the removal of the native signal sequence ( $\mathrm{PQR} 1711$ ), but rescued with a marginal improvement over the original following the addition of DsbA signal sequence (pQR1712).

To ensure extracellularly located C. violaceum glucoamylase remained active at typical $E$. coli culture temperatures, starch degradation was measured using amylase assays at temperatures ranging from 20 to $60{ }^{\circ} \mathrm{C}$ (Fig. 5). The enzyme's optimal activity was found to be at approximately $30{ }^{\circ} \mathrm{C}$, while still retaining $50 \%$ activity at $20^{\circ} \mathrm{C}$.

\section{Utilisation of starch as a sole carbon source by a glucose releasing amylolytic $E$. coli strain}

E. coli BL21(DE3) expressing the C. violaceum glucoamylase was able to grow in glucose free MSM containing starch as a sole carbon source (Fig. 6a). A culture period of $24 \mathrm{~h}$ led to $\mathrm{OD}_{600}$ values in excess of 1.5 for both pQR1708 (native signal sequence) and pQR1712 (DsbA signal sequence) grown in glucose free MSM containing $2.5 \mathrm{mg} / \mathrm{mL}$ starch. Conversely the 
a

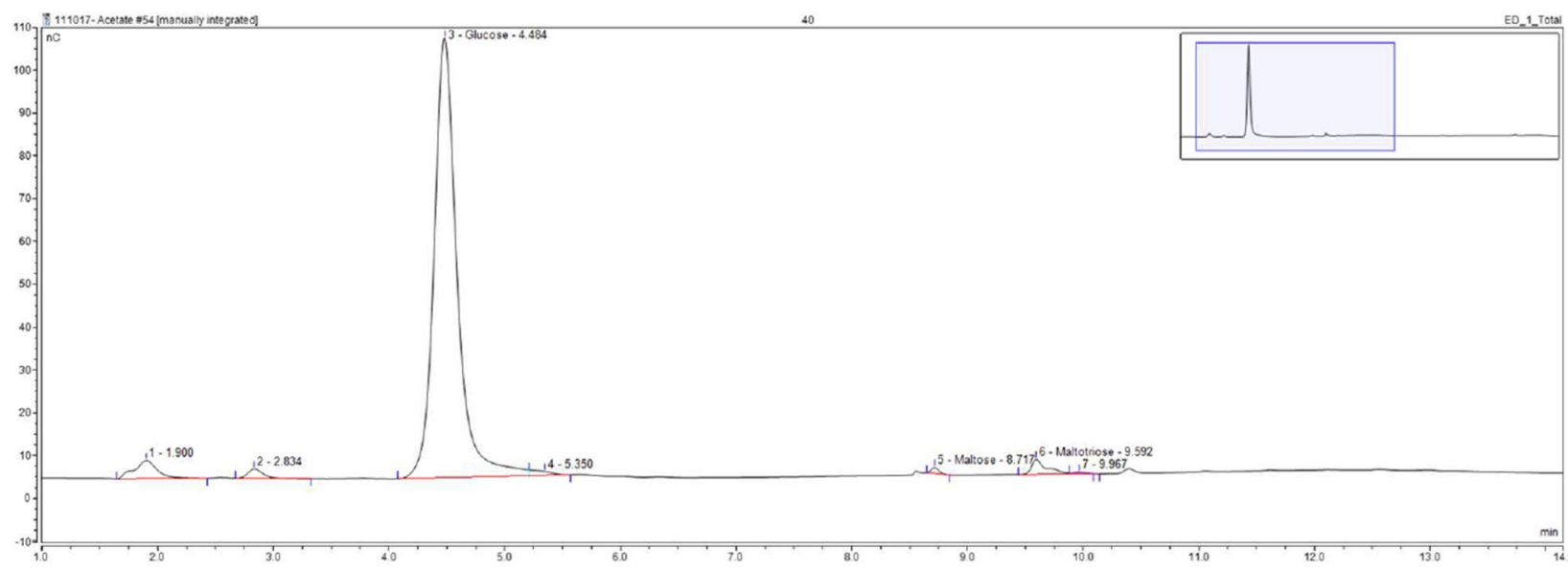

b

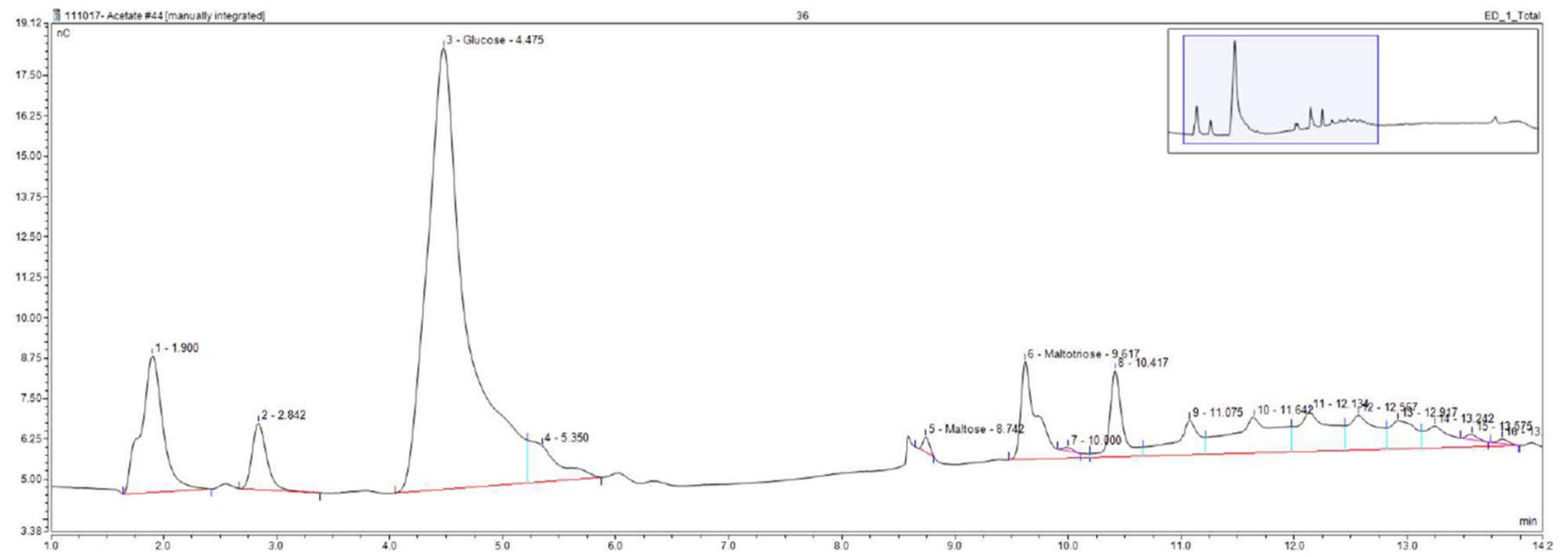

C

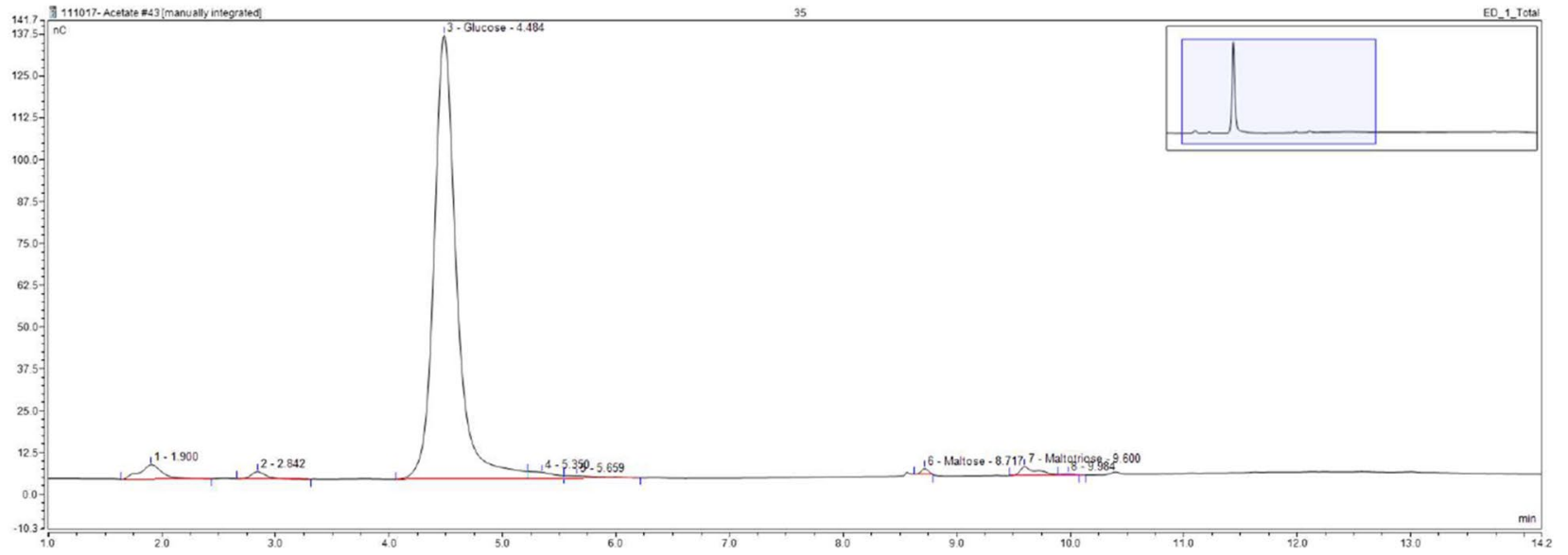

Fig. 3 Chromatograms of D. geothermalis, T.tengcongensis and C. violaceum glucoamylase hydrolysis products. Example ICS chromatograms for amylase assay samples removed after $1 \mathrm{~h}$, for clarified lysates of $E$. coli BL21(DE3) expressing a pQR1 706, b pQR1707, and c pQR1708, cultured in TB for $24 \mathrm{~h}$ at $25^{\circ} \mathrm{C}, 180 \mathrm{rpm}$ (induced with $0.4 \mathrm{mM}$ IPTG at an $\mathrm{OD}_{600}$ of 0.8 ) 

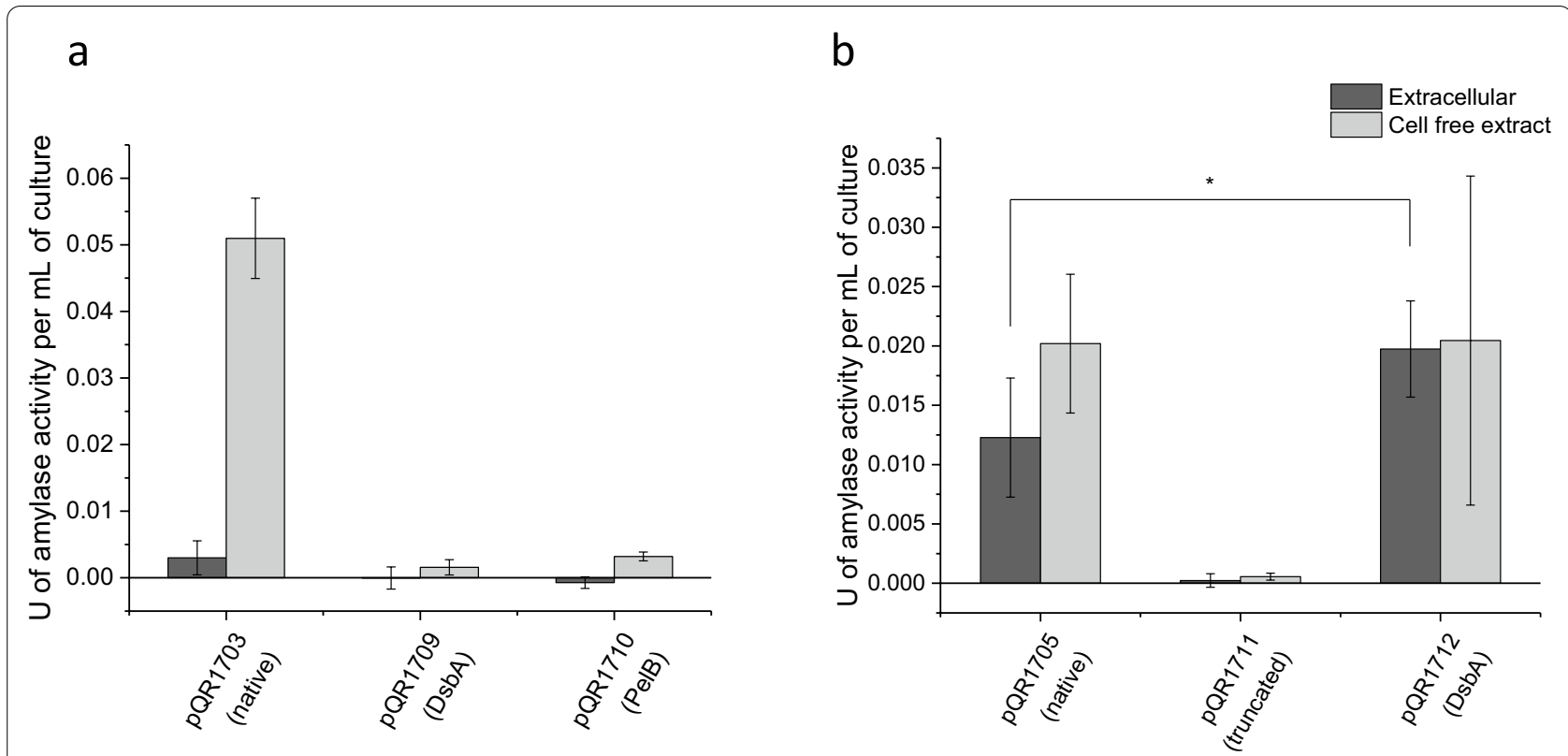

Fig. 4 Extracellular and cell free extract activities of D. geothermalis and C. violaceum glucoamylases following addition of exogenous signal sequences. Extracellular (dark grey) and cell free extract (light grey) activities expressed in units (defined as the disappearance of $1 \mathrm{mg} / \mathrm{mL}$ of starch/iodine complex per minute) per $\mathrm{mL}$ of culture. Constructs expressed in BL21(DE3) and cultured for $24 \mathrm{~h}$ at $25^{\circ} \mathrm{C}, 180 \mathrm{rpm}$ in LB (induced with 0.4 mM IPTG at an $\mathrm{OD}_{600}$ of 0.6-0.8). a pQR1703 (D. geothermalis glucoamylase), pQR1709 (D. geothermalis glucoamylase containing DsbAss) or pQR1710 (D. geothermalis glucoamylase containing PelB signal sequence). b pQR1705 (C. violaceum glucoamylase), pQR1711 (truncated C. violaceum glucoamylase) or PQR1712 (C. violaceum glucoamylase containing DsbA signal sequence). Error bars represent standard deviation, $\mathrm{n}=6$

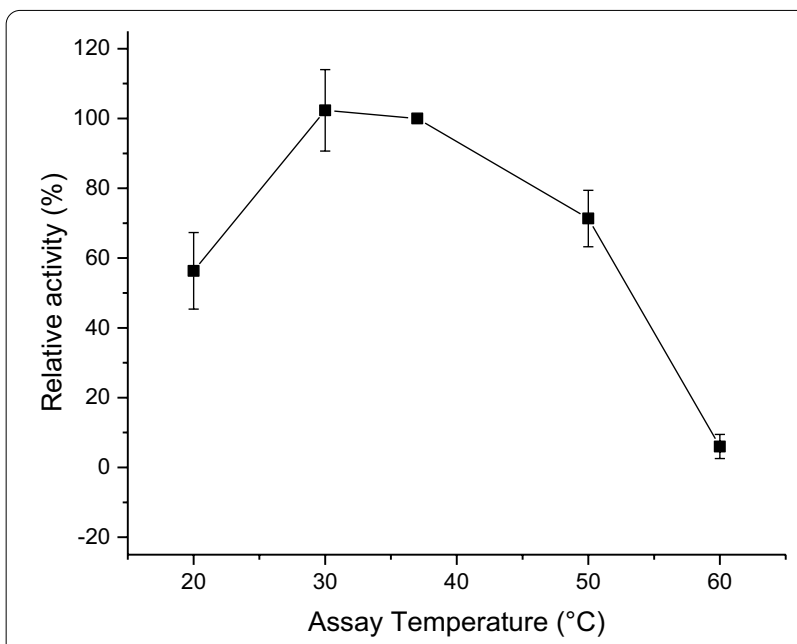

Fig. 5 Relative activity of $C$. violaceum glucoamylase with temperature. Extracellular activity of $C$. violaceum glucoamylase at varying temperatures $\left(20^{\circ} \mathrm{C}\right.$ to $\left.60^{\circ} \mathrm{C}\right)$ expressed as a percentage of the activity from the standard amylolytic assay carried out at $37^{\circ} \mathrm{C}$. Extracellular media samples for assays extracted from BL21(DE3) harbouring PQR1705 (C. violaceum glucoamylase) cultured in LB for $24 \mathrm{~h}$ at $25^{\circ} \mathrm{C}, 180 \mathrm{rpm}$ (induced with $0.4 \mathrm{mM}$ IPTG at an $\mathrm{OD}_{600}$ of 0.6-0.8). Activities within standard amylase assay determined by the change in absorbance of starch/iodine complex at $600 \mathrm{~nm}$. Error bars represent standard deviation, $\mathrm{n}=3$
BL21(DE3) control cultures did not achieve densities far beyond that of the initial inoculum density $\left(\mathrm{OD}_{600}\right.$ of 0.25). Alongside increases in cell density, starch degradation within the glucose free MSM was also significantly greater in the two glucoamylase expressing strains compared with the untransformed control, with over half of the available starch $(>1.5 \mathrm{mg} / \mathrm{mL})$ degraded in $24 \mathrm{~h}$ (Fig. 6b). A similar growth advantage for plasmid containing cells was seen in cultures of $E$. coli W3110 with and without the a-amylase expressing plasmid $\mathrm{pQR} 187$, Additional file 1: Fig S3.

Growth characteristics of BL21(DE3) harbouring pQR1712 were further explored using starch/agar layers in shake flasks (Additional file 1: Fig S4), significantly increasing the availability of starch within the glucose free MSM. These cultures achieved cell densities with an $\mathrm{OD}_{600}$ of approximately 15 (Fig. 7), equivalent to commonly used complex media such as LB or $\mathrm{TB}$, albeit over a longer culture period of $72 \mathrm{~h}$. However, compared to MSM flasks containing an equivalent amount of dissolved glucose (50 mg/mL), BL21(DE3) cells expressing glucoamylase cultured in media containing starch showed no advantage in terms of final cell densities achieved. 
a

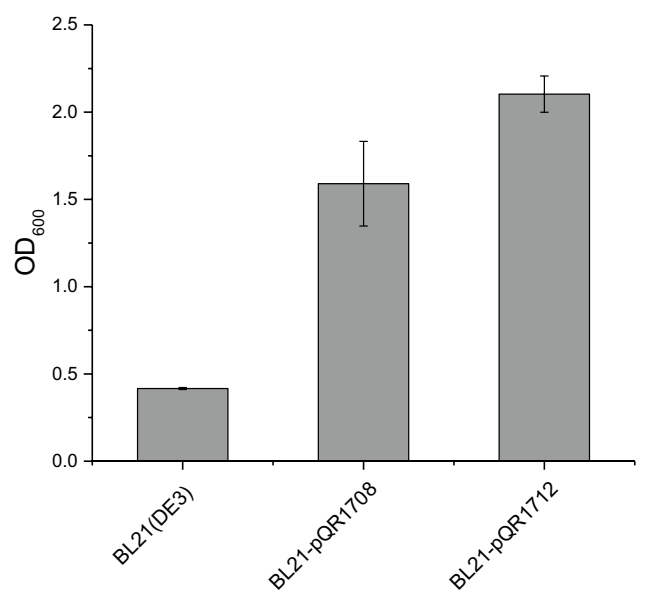

b

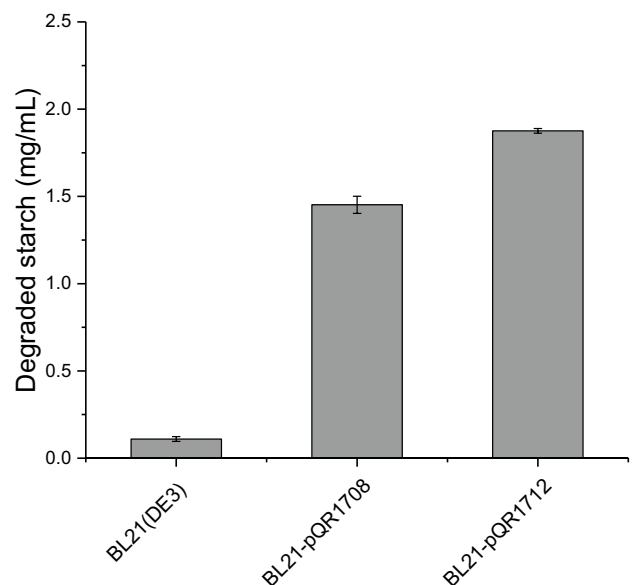

Fig. 6 Glucose releasing amyloltic E. coli strains and their utilisation of starch as a sole carbon source. E. coli BL21(DE3) harbouring either pQR1708 (native signal sequence) or pQR1712 (DsbA signal sequence) inoculated with an initial $\mathrm{OD}_{600}$ of 0.25 and cultured over a $24 \mathrm{~h}$ period at $30^{\circ} \mathrm{C}$, $250 \mathrm{rpm}$, in glucose free MSM supplemented with $2.5 \mathrm{mg} / \mathrm{mL}$ starch. a Cell density $\left(\mathrm{OD}_{600}\right)$ after $24 \mathrm{~h}$ of culture. b Amount of starch degraded (mg/ $\mathrm{mL}$ ) in culture media after $24 \mathrm{~h}$ of culture, determined by absorbance of starch/iodine complex at $600 \mathrm{~nm}$ in starch degradation assay. Error bars represent standard deviation, $\mathrm{n}=3$

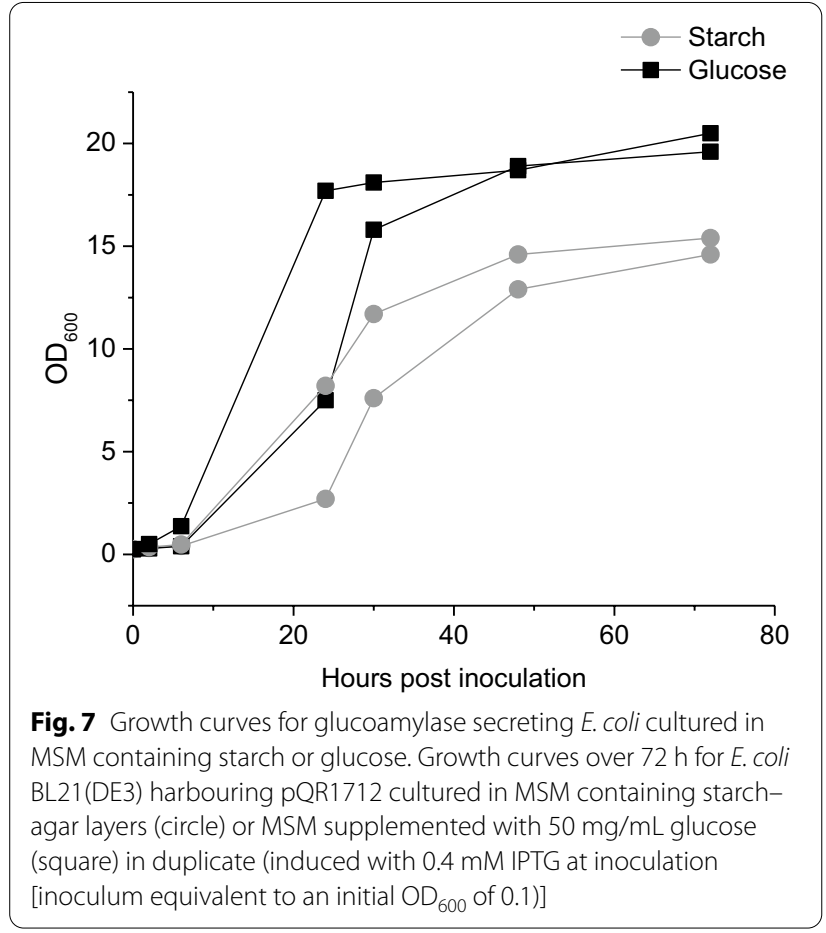

\section{Demonstration of self-secreting enzyme-based fed-batch} fermentation

E. coli BL21(DE3) is widely reported to be less susceptible to overflow metabolism than other strains such as W3110. A K12 compatible promoter was therefore used to investigate whether a glucose releasing W3110 amylolytic strain could achieve higher cell densities when cultured on starch as a carbon source compared with an equivalent amount of glucose. Expression from the glucose sensitive PcstA promoter was characterised by measuring extracellular glucoamylase activity following growth in LB containing varying concentrations of glucose. As the concentration of glucose increased, extracellular glucoamylase activity decreased, with a fourfold reduction in activity from 0 to $20 \mathrm{mM}$ glucose (Fig. 8).

The effect of self-regulated glucoamylase expression on growth was demonstrated using starch/agar layers (Additional file 1: Fig S4) and glucose free MSM in shake flasks. E. coli W3110 harbouring pQR1715 achieved substantially higher cell densities when cultured on starch $\left(\mathrm{OD}_{600}\right.$ of approx. 30), compared with an equivalent amount of glucose $\left(\mathrm{OD}_{600}\right.$ of approx. 15) (Fig. 9a). The associated extracellular glucoamylase activity was determined and expressed as both $U$ per $\mathrm{mL}$ of culture and $\mathrm{U}$ per $\mathrm{g}(\mathrm{DCW})$, with one Unit defined as the disappearance of $1 \mathrm{mg}$ of starch-iodine complex per minute. Surprisingly, throughout the culture period there was no difference in measured glucoamylase activity between starch and glucose media for either $\mathrm{U}$ per $\mathrm{mL}$ of culture (Fig. 9b) or $\mathrm{U}$ per $\mathrm{g}(\mathrm{DCW}$ ) (Fig. 9c). Both media types showed an initial increase in $\mathrm{U}$ per $\mathrm{mL}$ of culture for the first $30 \mathrm{~h}$ and then a subsequent plateau. When normalised to cell density activity decreased rapidly in the first $10 \mathrm{~h}$ and subsequently levelled off for the remainder of the culture period. 


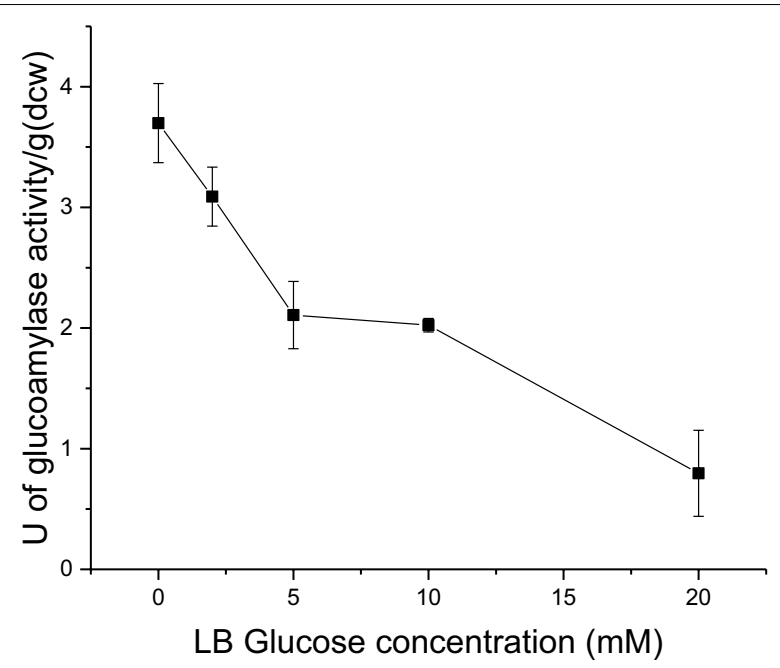

Fig. 8 Characterisation of PcstA regulated C. violaceum glucoamylase secretion in LB media supplemented with 0-20 mM glucose. Extracellular glucoamylase activity of E. coli W3110 harbouring pQR1715 (BBa_K118011-CV2DsbA) cultured for $24 \mathrm{~h}$ at $37^{\circ} \mathrm{C}$, $250 \mathrm{rpm}$, in LB containing a range of glucose concentrations (0-20 mM). Activity expressed as units (defined as the disappearance of $1 \mathrm{mg} / \mathrm{mL}$ of starch/iodine complex per minute) per gram of dry cell weight and determined by the change in absorbance of starch/ iodine complex at $600 \mathrm{~nm}$. Error bars represent standard deviation, $n=3$

To determine whether the increase in cell density reflected an increase in recombinant protein yield, a vector was designed to simultaneously express $C$. violaceum glucoamylase and a recombinant protein of interest in the form of eGFP (pQR1720). Figure 10 shows this plasmid where the GFP and glucoamylase are constructed to be in an operon and expressed from a lac promoter. Cultures containing starch consistently achieved larger increases in both cell density (Fig. 10a) and eGFP fluorescence (Fig. 10c, d) from 0 to $48 \mathrm{~h}$ compared with the glucose equivalent; the first demonstration of enhanced recombinant protein yield directly resulting from selfsecreting enzyme-based fed-batch fermentation.

\section{Discussion}

The characterisation of two novel $D$. geothermalis and the $C$. violaceum glucoamylase enzymes within this study revealed both were more exo-acting than the previously characterised $T$. tengcongensis glucoamylase, with high performance anion exchange chromatography data displaying an increased accumulation of glucose relative to longer chain oligosaccharides when the former hydrolysed starch. Furthermore, the mass balance of starch hydrolysis and glucose accumulation was less negative for both the $D$. geothermalis and the $C$. violaceum glucoamylases, than for the T. tengcongensis glucoamylase, suggesting an accumulation of product other than glucose for the latter enzyme.

The increased ability of the C. violaceum glucoamylase to be secreted into the extracellular media is likely explained by the presence of a native signal sequence, in contrast with the $D$. geothermalis glucoamylase, which did not contain a native signal sequence. The replacement of the native signal sequence from the $C$. violaceum glucoamylase with the DsbA signal sequence saw a marginal but still significant improvement in secretion. The fact that the $D$. geothermalis glucoamylase did not contain a recognisable native signal sequence suggests it is not usually exported and therefore was probably not the best candidate enzyme for an extracellular application. Indeed, despite the addition of the DsbA signal sequence or the PelB signal sequence, no activity in the extracellular media was detected, indicating that D. geothermalis glucoamylase is not easily secreted through either the SRP or Sec pathways. Conversely, the C. violaceum glucoamylase is naturally secreted, and apparently capable of secretion by $E$. coli via both the native signal sequence and the exogenous DsbA signal sequence. There are two slightly different routes that the standard E. coli signal sequences are recognised and processed. These are the SEC and SRP pathways. The PelB signal sequence is processed via the SEC pathway and the DsbA sequence is processed via the SRP pathway. In some cases the SRP signal sequence helps secretion of certain proteins which are not efficiently secreted by the SEC pathway. But in the case of D. geothermalis neither the SRP or the SEC pathway allowed secretion.

Secreted C. violaceum glucoamylase via either signal peptide showed considerable glucose releasing amylolytic activity in the extracellular media, enough to allow expression strains to degrade starch contained within the medium during growth. Furthermore, E. coli BL21(DE3) expressing and secreting $C$. violaceum glucoamylase was able to utilise starch as a sole carbon source, which to our knowledge is the first example of an engineered $E$. coli strain converting starch directly to glucose for the purpose of enhancing growth. To mimic fed-batch fermentation using the slow release of utilisable carbon, a combination of defined media (glucose free MSM) and starch-agar layers were developed alongside the C. violaceum glucoamylase E. coli W3110 expression strains. The secretion of $C$. violaceum glucoamylase was designed to be negatively regulated by its own hydrolysis product, theoretically maintaining a constant glucose concentration in the media throughout the culture, irrespective of cell density. A Cyclic Adenosine Monophosphate (cAMP) sensitive promoter (PcstA) was selected and characterised. PcstA itself, derived from E. coli JM109, is ordinarily involved in the regulation of carbon starvation response 


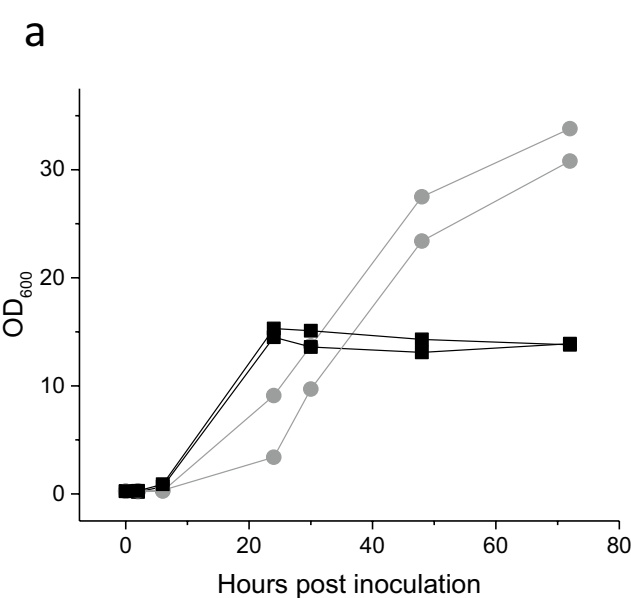

b

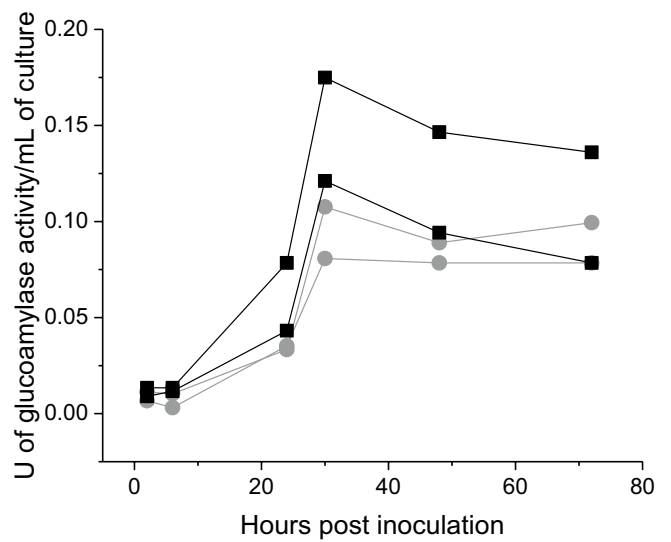

C

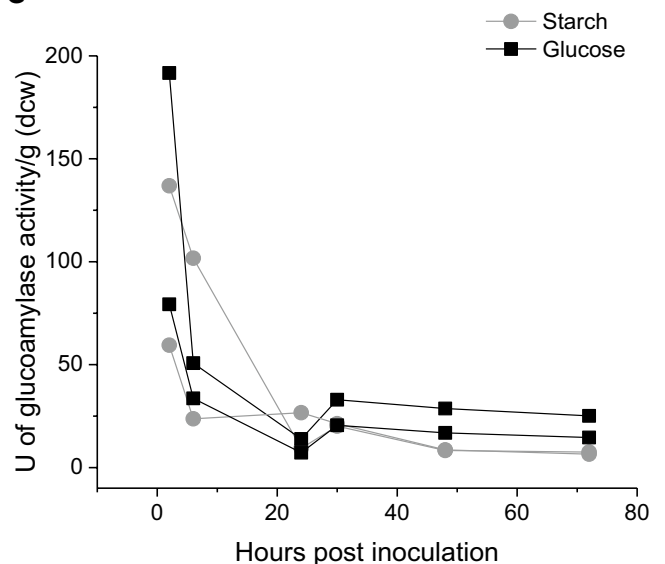

Fig. 9 PcstA regulated C. violaceum glucoamylase expression and its influence on growth in MSM containing starch-agar layers. E. coli W3110 harbouring pQR1715 (BBa_K118011-CV2DsbA) cultured for $72 \mathrm{~h}$ at $30^{\circ} \mathrm{C}, 180 \mathrm{rpm}$, in either glucose free MSM with starch-agar layers (circle) or MSM supplemented with $50 \mathrm{~g} / \mathrm{L}$ glucose (square). a Growth curves for each condition in duplicate. b Glucoamylase activity in the extracellular media determined by amylase assay at $37^{\circ} \mathrm{C}$ and expressed as units per $\mathrm{mL}$ of culture. c Glucoamylase activity in the extracellular media determined by amylase assay at $37^{\circ} \mathrm{C}$ and expressed as units per gram of dry cell weight. Units defined as the disappearance of $1 \mathrm{mg} / \mathrm{mL}$ of starch/ iodine complex per minute, determined by the change in absorbance of starch/iodine complex at $600 \mathrm{~nm}$

genes $($ cst $A)$ which are up regulated during glucose starvation [23]. The mechanism behind this is based on the ability of cAMP to induce conformational change in the catabolite gene activator protein (CAP), enhancing its binding to CAP-dependent promoters [24], and promoting expression. In the absence of glucose, levels of intracellular cAMP are increased [25], leading to the binding of CAP to the promotor and subsequent transcription of target genes. In high glucose concentrations, intracellular cAMP is reduced, leading to a reduction in bound CAP, and a subsequent reduction in gene transcription. E. coli W3110 expressing C. violaceum glucoamylase under the regulation of PcstA was capable of achieving densities approximately twice that of cultures grown in an equivalent amount of glucose; demonstrating increased cell densities as a direct result of self-regulated enzyme-based fed-batch fermentation.

The main caveat to this system however, is that, for shake flasks at least, the advantages may be specific to K12 strains, as BL21(DE3) appeared not to benefit from the slow release of glucose from starch, presumably because BL21(DE3), being a B strain of E. coli, does not demonstrate any detrimental effects in terms of growth from high concentrations of glucose in the first place. This is likely a result of the B strain's, BL21(DE3), ability to employ a glyoxylate shunt, reducing the accumulation of acetate and minimising the detrimental effects of overflow metabolism [26-30].

The data for the host strains with no plasmid versus the same hosts containing plasmids secreting the $C$. 
a

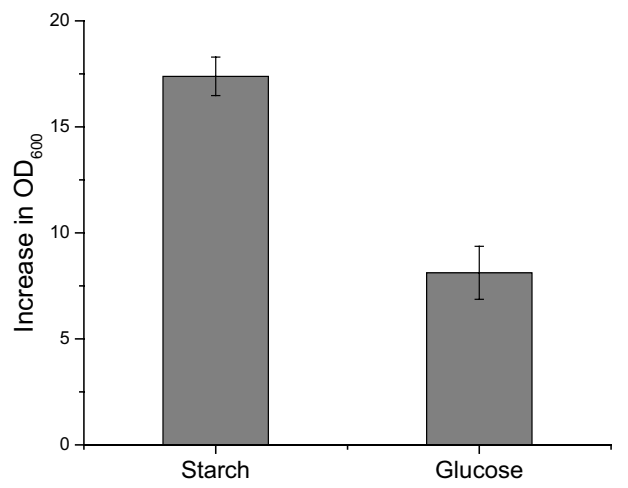

C

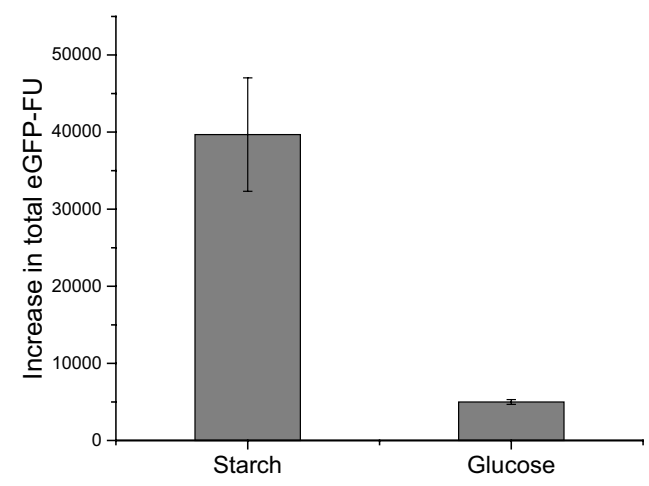

b

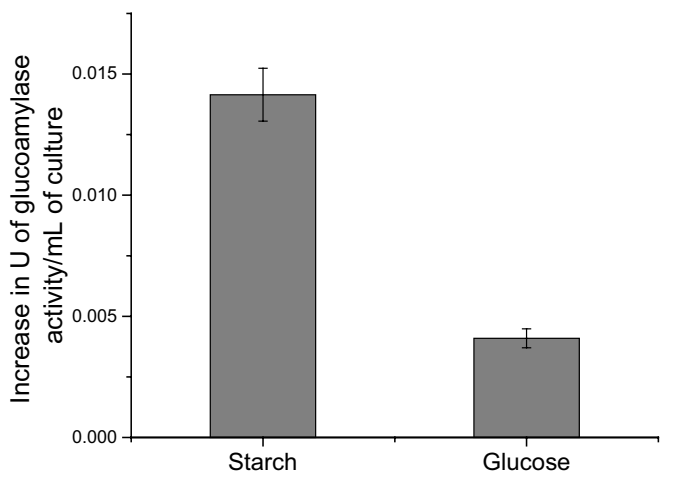

d

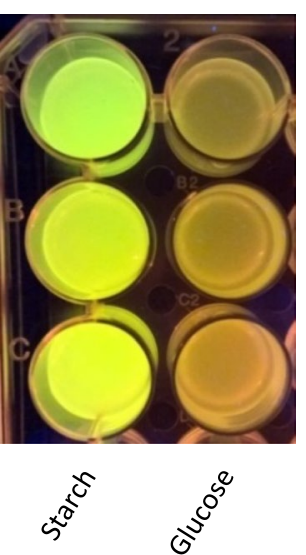

Fig. 10 Self secreting enzyme-based fed-batch fermentation via simultaneous expression of $C$. violaceum glucoamylase and eGFP in E. coli W3110. E. coli W3110 harbouring PQR1720, cultured in flasks containing glucose free MSM with starch-agar layers or MSM supplemented with $50 \mathrm{~g} / \mathrm{L}$ glucose, at $37^{\circ} \mathrm{C}, 250 \mathrm{rpm}$ for $48 \mathrm{~h}$ [induced with $0.4 \mathrm{mM}$ IPTG at inoculation (initial $\mathrm{OD}_{600}$ of 0.25$)$ ]. a Increase in cell density $\left(\mathrm{OD}_{600}\right)$ over $48 \mathrm{~h}$ of culture for each media type. $\mathbf{b}$ Increase in extracellular media glucoamylase activity over $48 \mathrm{~h}$ for each media type, expressed in units of glucoamylase activity per $\mathrm{mL}$ of culture, determined by amylase assay at $37^{\circ} \mathrm{C}$ and expressed as units per $\mathrm{mL}$ of culture. Units defined as the disappearance of $1 \mathrm{mg} / \mathrm{mL}$ of starch/iodine complex per minute, determined by the change in absorbance of starch/iodine complex at $600 \mathrm{~nm}$. c Increase in total eGFP fluorescence units over $48 \mathrm{~h}$ for each media type, measured from neat whole cell samples using an excitation wavelength of $483 \mathrm{~nm}$ and emission wavelength of $535 \mathrm{~nm}$ (Tecan infinite 200 pro). $\mathbf{d}$ Image of eGFP expression under blue light for each media composition, displayed in triplicate. Error bars represent standard deviation, $n=3$

violaceum glucoamylase or an alpha amylase in starch containing medium shows that in both cases the growth rate and final OD are significantly greater in the cells that have the plasmid. This shows that there is no 'burden' given by carriage and expression of the secreted enzymes in the system we are describing here. The data for the E. coli with and without the plasmid expressing C. violaceum glucoamylase in Fig. 6 and in Additional file 1: Figure S3 shows that an alpha-amylase expressing plasmid gives significantly higher growth rates and final OD compared to plasmid free cells in rich media with starch.
Finally, in an attempt to use the enhanced cell mass as a platform for recombinant protein expression, simultaneous expression of both an amylolytic enzyme and a recombinant protein of interest was investigated. Rather than using two separate vectors, both genes were expressed from the same vector. The rationale was that this would eliminate compatibility issues, reduce the metabolic burden associated with multiple antibiotic resistance genes, and simplify the transformation method. In addition it would also provide a basis for a versatile system whereby a plasmid already containing a self-regulated amylolytic enzyme could be designed to contain 
a multiple cloning site for the insertion of an additional gene of interest, similar in concept to current commercially available vectors such as pETDuet ${ }^{\mathrm{TM}}$ (Novagen) or pACYCDuet ${ }^{\mathrm{TM}}$ (Novagen), but specifically used for high density growth using starch as a substrate. The construction of $\mathrm{pQR} 1720$ which included an operon containing eGFP immediately followed by the C. violaceum glucoamylase (Fig. 11), regulated by the lac promoter, successfully demonstrated a recombinant protein expression system using starch as a sole carbon source. pQR1720 is based on pUC19 and is a very high copy number plasmid with approximately 500-700 copies per cell. The eGFP in pQR1720 is expressed from the lac promoter which is considerably weaker than the $\mathrm{T} 7$ promoter in the $\mathrm{pET}$ constructs. The previous constructs in pET are in a low/ medium copy number backbone giving 15-20 copies per cell. This is a 25 - to 45 -fold difference in gene dosage between pUC and pET ( $\mathrm{pUC} \gg \mathrm{pET}$ ) which evens out the influence of the weaker promoter. So although the promoter pPlac is weaker than the T7 promoter, the large increase in copy number makes up for this.

Furthermore, the yield of recombinant protein (eGFP) was greater in cultures containing starch than in cultures containing an equivalent amount of glucose; the first example of enhanced recombinant protein expression resulting directly from a cell engineered approach to enzyme-based fed-batch fermentation.

\section{Conclusion}

This study provides an innovative solution to a fundamental problem associated with microbial fermentation, achieving high cell densities and increased recombinant protein yields in batch culture. By combining the principles of enzyme-based fed-batch fermentation with engineered amylolytic $E$. coli strains, a proof of concept has been demonstrated which has the potential to provide an alternative to current traditional fed-batch methods. More broadly, this work highlights the capability of cell

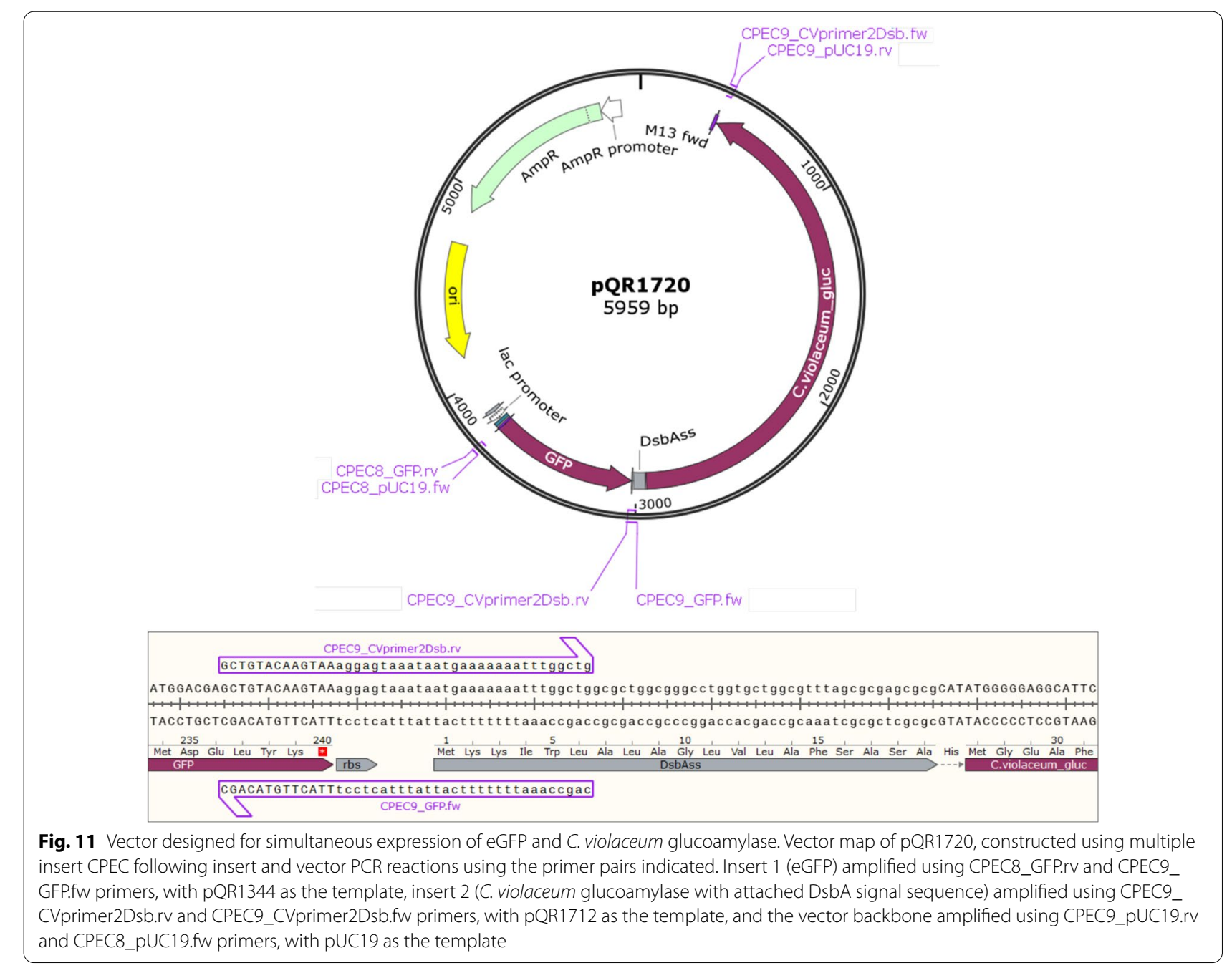


engineering to enhance bioprocessing, and provides a platform for further projects looking to combine this with other cell engineering approaches to improve overall bioprocessing efficiencies.

\section{Methods}

\section{Strains and plasmids}

E. coli strains used in this study were W3110 $\left(\mathrm{F}^{-} \lambda^{-} r p h\right.$ 1, Inv(rrnD, rrnE)) [72], and BL21(DE3) [73] (F- ompT, gal, dcm, lon, $h s d S_{B}\left(r_{B}{ }^{-} m_{B}{ }^{-}\right.$) 1(DE3 [lacI PlacUV5-T7p07 ind1 sam7 nin5]) (Novagen). HST08 (Stellar ${ }^{\mathrm{TM}}$ chemically competent, Clonetech) and TOP10 (chemically competent, Thermo Fisher Scientific) were used for subcloning experiments. All vectors, primers and oligonucleotides were designed using SnapGene (version 1.1.3) software. Oligonucleotides were synthesised and supplied by Eurofins Genomics. For use in PCR, lyophilised oligonucleotides were re-suspended in miliQ water and diluted to a concentration of $10 \mu \mathrm{M}$. For use in ligation, equimolar concentrations of complementary oligonucleotides were mixed, heated to $98{ }^{\circ} \mathrm{C}$ and allowed to cool to room temperature. Vectors were constructed using traditional restriction digestion and ligation or by circular polymerase extension cloning. Confirmation of correct construction was carried out by restriction analysis and sequencing (Eurofins Genomics). All strains were maintained and propagated using selective LB agar plates, supplemented with kanamycin $(20 \mu \mathrm{g} / \mathrm{mL})$, ampicillin $(50 \mu \mathrm{g} / \mathrm{mL})$ or chloramphenicol $(30 \mu \mathrm{g} / \mathrm{mL})$ (Table 1).

\section{Chromosomal DNA preparation}

Thermoanaerobacter tengcongensis was supplied lyophilised by The Leibniz Institute DSMZ (DSM number 15242 Caldanaerobacter subterraneus subsp. tengcongesis), and was re-suspended in $1 \mathrm{~mL}$ of $20 \%$ (w/v) glycerol. Chromobacterium violaceum and Deinococcus geothermalis were supplied by J. Ward as glycerol stocks. Chromosomal DNA was prepared by diluting the glycerol stocks 1 in 10 with sterile water. Lysozyme was added to this dilution to give a final concentration of $50 \mu \mathrm{g} /$ $\mathrm{mL}$ and the mixture was incubated at $37^{\circ} \mathrm{C}$ for $15 \mathrm{~min}$. SDS was then added to give a final concentration of $1 \%$ $(\mathrm{v} / \mathrm{v})$, turning the mixture clear and viscous. $250 \mu \mathrm{L}$ of this solution was combined with a vortexed mixture of P2 $(250 \mu \mathrm{L})$ and N3 $(350 \mu \mathrm{L})$ reagents (QIAprep Miniprep Kit, Qiagen) and centrifuged for $10 \mathrm{~min}$ at $17,000 \times g$. The supernatant was loaded onto a spin column (QIAprep Miniprep Kit, Qiagen) with the standard miniprep protocol followed from this point onwards. The genomic DNA was eluted with $100 \mu \mathrm{L}$ EB buffer, and used directly for PCR. Genomic DNA from D. geothermalis was provided by Dr Maria Bawn.

\section{Plasmid construction}

Glucoamylase genes from D. geothermalis, T. tengcongensis, and C. violaecium were amplified using PCR under standard conditions [Phusion ${ }^{\circledR}$ High-Fidelity PCR master mix with HF Buffer (New England Biolabs)]. With an annealing temperature gradient of $10^{\circ} \mathrm{C}$

Table 1 Constructs used within this study

\begin{tabular}{|c|c|c|}
\hline Plasmid & Description & References \\
\hline pET29a $(+)$ & T7 promoter, Kan', ability for C-terminal 6-His tag & Novagen \\
\hline pQR1344 & pET29a containing eGFP, T7 promoter, Kan ${ }^{r}$ & D. Dobrijevic (unpublished) \\
\hline pQR1703 & pET29a containing D. geothermalis glucoamylase, T7 promoter, Kan r & This study \\
\hline pQR1704 & pET29a containing T. tengcongensis glucoamylase, T7 promoter, Kan ${ }^{r}$ & This study \\
\hline pQR1705 & pET29a containing C. violaceum glucoamylase, T7 promoter, Kan ${ }^{r}$ & This study \\
\hline $\mathrm{pET} 28 \mathrm{a}(+)$ & T7 promoter, Kan', ability for N-terminal 6-His tag & Novagen \\
\hline pQR1706 & pET28a containing D. geothermalis glucoamylase, T7 promoter, Kan ${ }^{r}$ & This study \\
\hline pQR1707 & pET28a containing T. tengcongensis glucoamylase, T7 promoter, Kan ${ }^{r}$ & This study \\
\hline pQR1708 & pET28a containing C. violaceum glucoamylase, T7 promoter, Kan ${ }^{r}$ & This study \\
\hline pQR1709 & pQR1703 with DsbA signal sequence, T7 promoter, Kan ${ }^{r}$ & This study \\
\hline $\mathrm{pQR} 1710$ & pQR1703 with PelB signal sequence, T7 promoter, Kanr & This study \\
\hline pQR1711 & pQR1705 lacking native signal sequence, T7 promoter, Kan ${ }^{r}$ & This study \\
\hline pQR1712 & pQR1711 with DsbA signal sequence, T7 promoter, Kan ${ }^{r}$ & This study \\
\hline BBa_K118011 & pSB1C3 containing PCstA, Cam ${ }^{r}$ & iGEM 2016 Distribution Kit \\
\hline $\mathrm{pQR} 1715$ & $\begin{array}{l}\text { BBa_K118011 containing C. violaceum glucoamylase with attached DsbA signal } \\
\text { sequence, PcstA, Camr }\end{array}$ & This study \\
\hline pUC19 & lac promoter, Ampr & Yanisch-Perron et al. [31] \\
\hline pQR1720 & $\begin{array}{l}\text { pUC19 containing eGFP followed by C. violaceum glucoamylase with DsbA signal } \\
\text { sequence, lac promoter, Amp }{ }^{r}\end{array}$ & This study \\
\hline
\end{tabular}


$\left(5{ }^{\circ} \mathrm{C}\right.$ either side of the lowest primer $\mathrm{T}_{\mathrm{m}}$ ) each PCR produced bands of the expected size; $D$. geothermalis (2396 bp), T. tengcongensis (2111 bp), and C. violaecium (2624 bp). Following gel extraction and purification (QIAquick Gel Extraction Kit, Qiagen), DNA bands were digested with NdeI and XhoI (New England Biolabs) and ligated (T4 DNA ligase, New England Biolabs) to purified NdeI/XhoI digested pET29a or pET28a backbones (Novagen). The resultant constructs, pQR1703, pQR1704, pQR1705 and pQR1706, pQR1707, pQR1708 respectively, were confirmed through restriction digestion analysis and sequencing (Eurofins Genomics).

The addition of signal peptides to the D. geothermalis glucoamylase was carried out by annealing complementary oligo nucleotides corresponding to DsbA and PelB signal sequences (synthesised by Eurofins Genomics), with the $5^{\prime}$ end of the sense strand and the $3^{\prime}$ end of the antisense strand staggered to form a join compatible with an XbaI restriction site, and the $3^{\prime}$ end of the sense strand and the $5^{\prime}$ end of the antisense staggered for compatibility with an NdeI restriction site. A ribosome binding site and a spacer region were included between the $\mathrm{XbaI}$ restriction site and the start codon. Following XbaI/NdeI digestion of pQR1703 the annealed oligo nucleotides were ligated to the backbone forming $\mathrm{pQR} 1703-\mathrm{DsbA}$ and $\mathrm{pQR} 1703-\mathrm{PelB}$, designated pQR1709 and pQR1710 respectively. The addition of DsbA signal sequence to the $C$. violaceum glucoamylase first required the removal of the native sequence, using an alternative forward primer which excluded the native signal sequence but contained an NdeI site (including a start codon) in the overhanging region. The truncated gene was then cloned into pET29a forming $\mathrm{PQR} 1711$, which itself was used as the backbone for the insertion of annealed complementary oligo nucleotides, creating $\mathrm{pQR} 1711-\mathrm{DsbA}$, designated $\mathrm{pQR} 1712$.

Plasmids pQR1715 and pQR1720 were constructed using Circular Polymerase Extension Cloning (CPEC) [32]. Reactions were carried out in total volumes of $50 \mu \mathrm{L}$ containing $25 \mu \mathrm{L}$ Phusion ${ }^{\circledR}$ High-Fidelity PCR master mix with HF Buffer, purified vector (200 ng) combined with purified insert at a 1:1 molar ratio. The thermocycling conditions for CPEC reactions used an initial denaturation period of $30 \mathrm{~s}$ at $98{ }^{\circ} \mathrm{C}$, followed by cycles of denaturation $\left(98^{\circ} \mathrm{C}\right.$ for $\left.15 \mathrm{~s}\right)$, annealing $\left(55^{\circ} \mathrm{C}\right.$ for $\left.30 \mathrm{~s}\right)$, and extension $\left(72{ }^{\circ} \mathrm{C}\right.$ for $25 \mathrm{~s}$ per 1000 base pairs) and a final extension of $72{ }^{\circ} \mathrm{C}$ for $5 \mathrm{~min}$. One cycle was performed for single insert CPEC (pQR1715), but for multiple inserts (pQR1720) this was increased to 20 cycles. CPEC reaction product was used directly for transformation $(4 \mu \mathrm{L}$ CPEC product in $50 \mu \mathrm{L}$ competent cells; Table 2).

\section{Media and shake flask composition}

Miller's LB Broth (Sigma Aldrich), containing $10 \mathrm{~g} / \mathrm{L}$ Tryptone, $10 \mathrm{~g} / \mathrm{L} \mathrm{NaCl}$ and $5 \mathrm{~g} / \mathrm{L}$ yeast extract, was prepared by dissolving $25 \mathrm{~g}$ in $1 \mathrm{~L}$ of water. Terrific broth (Sigma Aldrich), containing $12 \mathrm{~g} / \mathrm{L}$ Tryptone, $24 \mathrm{~g} / \mathrm{L}$ yeast extract, $9.4 \mathrm{~g} / \mathrm{L} \mathrm{K}_{2} \mathrm{HPO}_{4}$, and $2.2 \mathrm{~g} / \mathrm{L} \mathrm{KH}_{2} \mathrm{PO}_{4}$, was prepared by dissolving $47.6 \mathrm{~g}$ plus an additional $8 \mathrm{~mL}$ of glycerol into $1 \mathrm{~L}$ of water. Both were autoclaved at $121{ }^{\circ} \mathrm{C}$ for $15 \mathrm{~min}$.

Glucose free mineral salt medium (MSM) was adapted from Krause et al. [9] and was prepared by dissolv-

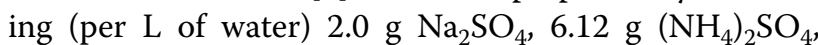
$0.50 \mathrm{~g} \mathrm{NH}_{4} \mathrm{Cl}, 14.60 \mathrm{~g} \mathrm{~K}_{2} \mathrm{HPO}_{4}, 3.60 \mathrm{~g} \mathrm{NaH}_{2} \mathrm{PO}_{4} \cdot \mathrm{H}_{2} \mathrm{O}$, $1.00 \mathrm{~g}_{\left(\mathrm{NH}_{4}\right)_{2}-\mathrm{H} \text {-citrate, } 3 \mathrm{mM} \mathrm{MgSO}}, 0.1 \mathrm{~g}$ thiamine hydrochloride, and $2 \mathrm{~mL}$ of SM6 trace element solution (composed of $104 \mathrm{~g} / \mathrm{L}$ Citric acid, $5.22 \mathrm{~g} / \mathrm{L} \mathrm{CaCl} \cdot 2 \mathrm{H}_{2} \mathrm{O}$, $2.06 \mathrm{~g} / \mathrm{L} \mathrm{ZnSO}_{4} \cdot 7 \mathrm{H}_{2} \mathrm{O}, 2.72 \mathrm{~g} / \mathrm{L} \mathrm{MnSO}_{4} \cdot 4 \mathrm{H}_{2} \mathrm{O}, 0.81 \mathrm{~g} / \mathrm{L}$ $\mathrm{CuSO}_{4} \cdot 5 \mathrm{H}_{2} \mathrm{O}, \quad 0.42 \mathrm{~g} / \mathrm{L} \quad \mathrm{CoSO}_{4} \cdot 7 \mathrm{H}_{2} \mathrm{O}, 10.06 \mathrm{~g} / \mathrm{L}$ $\left.\mathrm{FeCl}_{3} \cdot 6 \mathrm{H}_{2} \mathrm{O}, 0.03 \mathrm{~g} / \mathrm{L} \mathrm{H}_{3} \mathrm{BO}_{3}, 0.02 \mathrm{~g} / \mathrm{L} \mathrm{Na}_{2} \mathrm{MoO}_{4} \cdot 2 \mathrm{H}_{2} \mathrm{O}\right)$. The solution was filter sterilised using $0.22 \mu \mathrm{m}$ Millipore Express $^{\mathrm{TM}}$ PLUS stericup ${ }^{\circledR}$ with a vacuum pump. MSM was prepared in three formats, either glucose free MSM, MSM supplemented with $2.5 \mathrm{mg} / \mathrm{mL}$ glucose (Sigma), or MSM supplemented with $2.5 \mathrm{mg} / \mathrm{mL}$ starch (soluble potato starch, Sigma). To assist with dissolving starch the latter required pre-autoclaved water containing enough starch for a final concentration of $2.5 \mathrm{mg} / \mathrm{mL}$ prior to addition of the other constituents and filter sterilisation.

Starch-agar layers were prepared within $500 \mathrm{~mL}$ baffled shake flasks, and were used in conjunction with glucose free MSM media. Firstly, a $50 \mathrm{~mL}$ solution of $50 \mathrm{mg} /$ $\mathrm{mL}$ starch and $2 \mathrm{mg} / \mathrm{mL}$ agar was added to the flask and autoclaved at $121{ }^{\circ} \mathrm{C}$ for $15 \mathrm{~min}$. Once cooled, $50 \mathrm{~mL}$ of pre-autoclaved $50 \mathrm{mg} / \mathrm{mL}$ agar was poured on top of the original layer and allowed to cool. Finally, $50 \mathrm{~mL}$ of glucose free MSM was added to the flask, remaining above the layers (Additional file 1: Figure S4).

\section{Growth and expression studies}

All shake flasks used for growth and expression studies were inoculated with either a 1 in 20 dilution from an overnight culture, or inoculated to an initial $\mathrm{OD}_{600}$ of 0.1 or 0.25 . Overnight cultures were generally $5 \mathrm{~mL} \mathrm{LB}$ in a $50 \mathrm{~mL}$ falcon tube (containing appropriate antibiotic) seeded from a glycerol stock, and grown at $37^{\circ} \mathrm{C}$ at $250 \mathrm{rpm}$. Unless otherwise stated, $500 \mathrm{~mL}$ baffled conical shake flasks were used, containing $50 \mathrm{~mL}$ of selected media, and in some cases the starch/agar layers described previously. In addition to media, an antibiotic, if needed, was supplied at the following concentrations: kanamycin $(20 \mu \mathrm{g} / \mathrm{mL})$; ampicillin $(50 \mu \mathrm{g} / \mathrm{mL})$; chlorampheni$\mathrm{col}(30 \mu \mathrm{g} / \mathrm{mL})$. For induction of all inducible promoters used in this study, $0.4 \mathrm{mM}$ IPTG was added when the 
Table 2 Nucleotide sequences of primers and oligonucleotides used in vector construction

\begin{tabular}{|c|c|c|}
\hline Primer/oligo & Nucleotide sequence & $\begin{array}{l}\text { Vector(s) } \\
\text { constructed }\end{array}$ \\
\hline ABF45027.fw & ATTCGACATATGA GT GACGCTTCCGC & $\begin{array}{l}\text { pQR1703, } \\
\text { pQR1706 }\end{array}$ \\
\hline ABF45027.rv & ATCAAGCTCGAGTCACCCGTTCT GCGCG & $\begin{array}{l}\mathrm{pQR} 1703, \\
\mathrm{pQR} 1706\end{array}$ \\
\hline Q8R917_3.Fw & ATTCGA CATATGTTGAA GA GGATT GGAAT & $\begin{array}{l}\text { pQR1704, } \\
\text { pQR1707 }\end{array}$ \\
\hline Q8R917_3.Rv & $\begin{array}{l}\text { ATCAAGCTCGAGTTATCTCTCCCCTAATAC } \\
\text { ATAC }\end{array}$ & $\begin{array}{l}\text { pQR1704, } \\
\text { pQR1707 }\end{array}$ \\
\hline AAQ61151.fw & ATTCGACATATGAAACACCCGTCCCTG & $\begin{array}{l}\mathrm{pQR} 1705, \\
\mathrm{pQR} 1708\end{array}$ \\
\hline AAQ61151.rv & $\begin{array}{l}\text { ATCAAGCTCGAGTCACCA GTTCACCTGATC } \\
\text { AT }\end{array}$ & $\begin{array}{l}\mathrm{pQR} 1705, \\
\mathrm{pQR} 1708\end{array}$ \\
\hline AAQ61151.rv & $\begin{array}{l}\text { ATCAAGCTCGAGTCACCA GTTCACCTGATC } \\
\text { AT }\end{array}$ & pQR1711 \\
\hline AAQ61151_2.fw & ATTCGACATATGGGGGA GGCATTCGGC & pQR1711 \\
\hline K118011-CVprimer2-Dsb & TTCCCCTCTAGAAGGAGTAAATAA & $\mathrm{pQR} 1715$ \\
\hline K118011_CV1.rv & ATCAA $\underline{\text { GGATCCTCACCA GT TCA CCT GAT }}$ & pQR1715 \\
\hline K118011Bamh1.fw & CATGATGGATCCTCCGGCAAAAAAGGGC & pQR1715 \\
\hline K118011Bamh1.rv & GGCCGCTACTAGTATGTC & $\mathrm{pQR} 1715$ \\
\hline CPEC8_GFP.rv & CACACAGGAAACA GCTATGGTGA GCAA GG & $\mathrm{pQR} 1720$ \\
\hline CPEC8_pUC19.fw & CCTTGCTCACCATA GCT GTTTCCT GT GT G & pQR1720 \\
\hline CPEC9_CVprimer2Dsb.fw & ACGGCCA GT GAATTCTCA CCA GTTCAC & pQR1720 \\
\hline CPEC9_CVprimer2Dsb.rv & $\begin{array}{l}\text { GCTGTACAA GTAAA GGA GTAAATAATGAAA } \\
\text { AAAATTTGGCTG }\end{array}$ & $\mathrm{pQR} 1720$ \\
\hline CPEC9_GFP.fw & $\begin{array}{l}\text { CAGCCAAATTTTTTTCATTATTTACTCCTTT } \\
\text { ACTTGTACAGC }\end{array}$ & $\mathrm{pQR} 1720$ \\
\hline CPEC9_pUC19.rv & GTGAACTGGTGA GAATTCACT GGCCGT & $\mathrm{pQR} 1720$ \\
\hline DsbAss upper & $\begin{array}{l}\text { CTAGAAGGA GTAAATAATGAAAAAAATTT } \\
\text { GGCTGGCGCTGGCGGGCCTGGTGCTGGCGT } \\
\text { TTAGCGCGAGCGCGCA }\end{array}$ & $\begin{array}{l}\mathrm{pQR} 1709, \\
\mathrm{pQR} 1712\end{array}$ \\
\hline DsbAss lower & $\begin{array}{l}\text { TATGCGCGCTCGCGCTAAACGCCAGCACCA } \\
\text { GGCCCGCCAGCGCCAGCCAAATTTTTTCAT. } \\
\text { TATTTACTCCTT }\end{array}$ & $\begin{array}{l}\mathrm{pQR} 1709, \\
\mathrm{pQR} 1712\end{array}$ \\
\hline PelBss upper & $\begin{array}{l}\text { CTAGAAGGAGTAAATAATGAAATATCTGCT } \\
\text { GCCGACCGCGGCGGCGGGCCTGCTGCTGCT } \\
\text { GGCGGCGCAGCCGGCGATGGCGCA }\end{array}$ & pQR1710 \\
\hline PelBss lower & $\begin{array}{l}\text { TATGCGCCATCGCCGGCTGCGCCGCCAGCA } \\
\text { GCAGCAGGCCCGCCGCCGCGGTCGGCAGCA } \\
\text { GATATTTCATTATTTACTCCT }\end{array}$ & pQR1710 \\
\hline
\end{tabular}


Table 2 (continued)

Restriction sites indicated by underlined bold (CATATG $=$ Ndel, CTCGAG $=$ Xhol, TCTAGA $=$ Xbal, GGATCC $=$ BamHI, ACTAGT $=$ Spel) Signal sequence dashed underlined, and ribosome binding site green underlined. The DsbAss upper and DsbAss lower are long oligos designed to anneal to one another and create a double stranded DNA fragment with an Xbal sticky end and an Ndel site at the other end. The PelB upper and lower anneal to also have Xbal and Ndel sticky ends. There is a ribosome binding site, AGGAG, and a spacer region, TAAATA, included between the Xbal restriction site and the start codon

culture had reached an $\mathrm{OD}_{600}$ of $0.6-0.8$, or at inoculation, for growth experiments involving amylolytic strains. Shake flask cultures were carried out at varying temperatures and durations depending on the nature of the experiment (see individual experiment for detail), but all were performed in a standard orbital incubated shaker (innova $^{\text {TM }} 4330$, New Brunswick Scientific) at either 250 or $180 \mathrm{rpm}$.

Cell free extract-samples $(1 \mathrm{~mL})$ of culture were centrifuged at $17,000 \times g$ for $5 \mathrm{~min}$. The resultant pellet was re-suspended in $300 \mu \mathrm{L}$ phosphate buffered saline (PBS) (pH7.4) and sonicated (3 cycles of $20 \mathrm{~s}$ on, $20 \mathrm{~s}$ off with an amplitude of 10 microns, MSE Soniprep 150). The ensuing whole cell fraction was further centrifuged at $17,000 \times g$ for $5 \mathrm{~min}$ and the supernatant collected as the clarified lysate.

Extracellular fraction-for the determination of secreted amylolytic enzyme within the extracellular media, $1 \mathrm{~mL}$ of culture was centrifuged at $17,000 \times g$ for 5 min with the resultant supernatant collected as the extracellular media fraction. To quantify activity from this fraction, samples were directly added to the amylase assay.

\section{Amylolytic activity assays}

Amylolytic activity was determined by measuring the rate of degradation of starch-iodine complex, a method adjusted from Blanchin-Roland and Masson [33], or the resulting accumulation of glucose via high performance anion exchange chromatography with pulsed amperometric detection (HPAEC-PAD) analysis. Unless otherwise stated amylolytic activity assays were set up using a $50 \mu \mathrm{L}$ sample of extracellular media or cell free extract made up to $0.5 \mathrm{~mL}$ with $15 \mathrm{mM}$ sodium phosphate buffer (pH5.8), and incubated at $37{ }^{\circ} \mathrm{C}$ with $0.5 \mathrm{~mL}$ starch solution $[5 \mathrm{mg} / \mathrm{mL}$ starch in $15 \mathrm{mM}$ sodium phosphate buffer (pH5.8)]. Subsequent $50 \mu \mathrm{L}$ samples were then taken at numerous time points and added to $1 \mathrm{~mL}$ of potassium iodide/iodine solution [freshly prepared by adding $200 \mu \mathrm{L} 2.2 \% \mathrm{I}_{2} / 4.4 \% \mathrm{KI}(\mathrm{w} / \mathrm{v})$ into $100 \mathrm{~mL}$ of $2 \%(\mathrm{w} / \mathrm{v}) \mathrm{KI}$ solution] with the corresponding decrease in absorbance at $600 \mathrm{~nm}$ measured. One unit of enzyme activity was defined as the disappearance of $1 \mathrm{mg} / \mathrm{mL}$ of starch-iodine complex per minute at $37{ }^{\circ} \mathrm{C}$. In addition, samples were also taken for HPAEC-PAD analysis, for the detection and quantitation of mono- and small chain oligosaccharides resulting from the amylolytic hydrolysis of starch.
Detection was carried out by injecting $25 \mu \mathrm{L}$ samples into a Reagent-Free Ion Chromatography System (ICS $5000+$, Dionex) equipped with a Dionex CarboPac ${ }^{\text {TM }}$ PA100 anion exchange column $(2 \times 250 \mathrm{~mm})$ fitted with a Dionex CarboPac ${ }^{\mathrm{TM}}$ PA100 guard column $(2 \times 50 \mathrm{~mm})$, and an electrochemical detector system. Elution was carried out using a linear gradient of $100 \mathrm{mM} \mathrm{NaOH}$ at $0 \mathrm{~min}$, to $60 \mathrm{mM} \mathrm{NaOH}$ and $400 \mathrm{mM} \mathrm{NaOAc}$ at $18 \mathrm{~min}$, followed by a step of $40 \mathrm{mM} \mathrm{NaOH}$ and $600 \mathrm{mM} \mathrm{NaOAc}$ for a further $2 \mathrm{~min}$. The column was re-equilibrated for $5 \mathrm{~min}$ with $100 \mathrm{mM} \mathrm{NaOH}$. The flow rate remained at $0.25 \mathrm{~mL} \mathrm{~min}^{-1}$ with a system pressure of approximately 2500 psi. Data collection and analysis was performed with Chromeleon software version 7.

Starch degradation within culture media was determined using an adaptation of the amylolytic activity assay described previously, whereby a $50 \mu \mathrm{L}$ sample of clarified culture media was added directly to $1 \mathrm{~mL}$ of potassium iodide/iodine solution [freshly prepared by adding $200 \mu \mathrm{L} 2.2 \% \mathrm{I}_{2} / 4.4 \% \mathrm{KI}(\mathrm{w} / \mathrm{v})$ into $100 \mathrm{~mL}$ of $2 \%(\mathrm{w} / \mathrm{v})$ KI solution]. The absorbance was measured against a potassium iodide/iodine solution blank at $600 \mathrm{~nm}$, with a standard curve prepared to determine concentration. For concentrations of starch beyond the linear range of the spectrophotometer the sample of clarified culture media was diluted appropriately and added to the potassium iodide/iodine solution in the same ratio.

Fluorescence measurements-fluorescence intensity of eGFP from samples of neat cell culture dispensed in either 24 or 96 microwell plates, were measured using excitation and emission wavelengths of $483 \mathrm{~nm}$ and $535 \mathrm{~nm}$ respectively (Tecan Infinite M200 Pro). Gain was optimised for each experiment conducted. Fluorescence units were displayed either irrespective of cell density, or were normalised to OD600 depending on the specific experiment conducted.

\section{Supplementary Information}

The online version contains supplementary material available at https://doi. org/10.1186/s12934-021-01634-y.

Additional file 1: Figure S1. Alignment of the glucoamylases from Thermoanaerobacter tengcongensis MB4, Deinococcus geothermalis and Chromobacterium violaecum. Figure S2. Crude (whole cell) and clarified lysates analysed on SDS page for pQR1706, pQR1707 and pQR1708. Figure S3. Growth curves of a-amylase secreting $E$. coli compared to plasmid free $E$. coli cultured in commercially available high cell density media. Figure S4. Design of starch-agar layer system for sufficient provision of carbon for high cell density applications. 


\section{Acknowledgements}

We thank Dr. Dragana Dobrijevic for providing PQR1344 and Dr. Maria Bawn for providing the D. geothermalis genomic DNA.

\section{Authors' contributions}

MS performed the experiments and wrote the manuscript with JMW. JMW conceived the study and MS and JMW planned and designed the experiments. All authors read and approved the final manuscript.

\section{Funding}

MS was funded by an EPSRC PhD grant EP/K503332/1. JMW has funding from BBSRC BB/L007444/1 and BB/J019445/1.

\section{Availability of data and materials}

Data generated or analysed during this study are included in this published article. Any further data analysed for this study are available from the corresponding author.

\section{Declarations}

\section{Competing interests}

The authors declare no competing interests.

Received: 30 June 2020 Accepted: 16 July 2021

Published online: 24 July 2021

\section{References}

1. Åkesson M, et al. On-line detection of acetate formation in Escherichia coli cultures using dissolved oxygen responses to feed transients. Biotechnol Bioeng. 1999;64:590-8.

2. Luli GW, StrohI WR. Comparison of growth, acetate production, and acetate inhibition of Escherichia coli strains in batch and fed-batch fermentations. Appl Environ Microbiol. 1990;56:1004-11.

3. Bauer KA, et al. Improved expression of human interleukin-2 in high-celldensity fermentor cultures of Escherichia coli K-12 by a phosphotransacetylase mutant. Appl Environ Microbiol. 1990;56:1296-302.

4. Yee L, Blanch HW. Recombinant protein expression in high cell density fed-batch cultures of Escherichia coli. Bio/Technology. 1992;10:1550-6.

5. Betts Jl, Baganz F. Miniature bioreactors: current practices and future opportunities. Microb Cell Fact. 2006;5:21-35.

6. Tyrrell EA, Mac Donald RE, Gerhardt P. Biphasic system for growing bactreia in concentrated culture. J Bacteriol. 1958;75:1-4

7. Lübbe C, Demain AL, Bergman K. Use of controlled-release polymer to feed ammonium to Streptomyces clavuligerus cephalosporin fermentations in shake flasks. Appl Microbiol Biotechnol. 1986;23:411.

8. Jeude $M$, et al. Fed-batch mode in shake flasks by slow-release technique. Biotechnol Bioeng. 2006;95:433-45.

9. Krause $M$, et al. A novel fed-batch based cultivation method provides high cell-density and improves yield of soluble recombinant proteins in shaken cultures. Microb Cell Fact. 2010;9:1-11.

10. Panula-Perala J, et al. Enzyme controlled glucose auto-delivery for high cell density cultivations in microplates and shake flasks. Microb Cell Fact. 2008;7:31-45.

11. Neubauer $P$, Neubauer A, Vasala A. Enzyme-based fed-batch technique in liquid cultures. Google Patents; 2010. US20120045836A1.

12. Henrissat B, Davies G. Structural and sequence-based classification of glycoside hydrolases. Curr Opinion Struct Biol. 1997;7:637-44.
13. Norouzian D, et al. Fungal glucoamylases. Biotechnol Adv. 2006;24:80-5.

14 Coutinho PM, Reilly PJ. Glucoamylase structural, functional, and evolutionary relationships. Proteins Struct Funct Bioinform. 1997;29:334-47.

15. Kobayashi F, Nakamura Y. Efficient production by Escherichia coli of recombinant protein using salting-out effect protecting against proteolytic degradation. Biotechnol Lett. 2003;25:779-82.

16. Zheng Y, et al. Cloning, expression, and characterization of a thermostable glucoamylase from Thermoanaerobacter tengcongensis MB4. Appl Microbiol Biotechnol. 2010;87:225-33.

17 Cantarel BL, et al. The carbohydrate-active enzymes database (CAZy): an expert resource for glycogenomics. Nucl Acid Res. 2009;37(Database issue):D233-8.

18. Luirink J, Dobberstein B. Mammalian and Escherichia coli signal recognition particles. Mol Microbiol. 1994;11:9-13.

19. Schierle CF, et al. The DsbA signal sequence directs efficient, cotranslational export of passenger proteins to the Escherichia coli periplasm via the signal recognition particle pathway. J Bacteriol. 2003;185:5706-13.

20. Lei SP, et al. Characterization of the Erwinia carotovora pelB gene and its product pectate lyase. J Bacteriol. 1987;169:4379-83.

21. Valent QA. Signal recognition particle mediated protein targeting in Escherichia coli. Antonie Van Leeuwenhoek. 2001;79:17-31.

22. Fekkes $P$, Driessen AJM. Protein targeting to the bacterial cytoplasmic membrane. Microbiol Mol Biol Rev. 1999;63:161-73.

23. Schultz JE, Matin A. Molecular and functional characterization of a carbon starvation gene of Escherichia coli. J Mol Biol. 1991;218:129-40.

24. Busby S, Ebright $\mathrm{RH}$. Transcription activation by catabolite activator protein (CAP). J Mol Biol. 1999:293:199-213.

25. Notley-McRobb L, Death A, Ferenci T. The relationship between external glucose concentration and CAMP levels inside Escherichia coli: implications for models of phosphotransferase-mediated regulation of adenylate cyclase. Microbiol. 1997;143:1909-18.

26. Noronha SB, et al. Investigation of the TCA cycle and the glyoxylate shunt in Escherichia coli BL21 and JM109 using 13C-NMR/MS. Biotechnol Bioeng. 2000;68:316-27.

27. Phue J-N, et al. Evaluating microarrays using a semiparametric approach: application to the central carbon metabolism of Escherichia coli BL21 and JM109. Genomics. 2007;89:300-5.

28. Phue J-N. Glucose metabolism at high density growth of E. coli B and E. coli K: differences in metabolic pathways are responsible for efficient glucose utilization in E. coli B as determined by microarrays and Northern blot analyses. Biotechnol Bioeng. 2005;90:805-20.

29. Shiloach J, et al. Effect of glucose supply strategy on acetate accumulation, growth, and recombinant protein production by Escherichia coli BL21 (XDE3) and Escherichia coli JM109. Biotechnol Bioeng. 1996:49:421-8.

30. van de Walle M, Shiloach J. Proposed mechanism of acetate accumulation in two recombinant Escherichia coli strains during high density fermentation. Biotechnol Bioeng. 1998;57:71-8.

31. Yanisch-Perron C, Vieira J, Messing J. Improved M13 phage cloning vectors and host strains: nucleotide sequences of the M13mpl8 and pUC19 vectors. Gene. 1985:33:103-19.

32. Quan J, Tian J. Circular polymerase extension cloning of complex gene libraries and pathways. PLoS ONE. 2009;4(7):e6441.

33. Blanchin-Roland S, Masson J-M. Protein secretion controlled by a synthetic gene in Escherichia coli. Protein Eng. 1989;2:473-80.

\section{Publisher's Note}

Springer Nature remains neutral with regard to jurisdictional claims in published maps and institutional affiliations. 